\title{
Comparative antiplaque and antigingivitis efficacy of three antiseptic mouthrinses: a two week randomized clinical trial
}

\section{Pejmon Amini(a) \\ Marcelo Werneck Barata Araujo(b) Mei-Miau Wu $\mathbf{W}^{(\mathrm{b})}$ \\ Christine Ann Charles ${ }^{(b)}$ \\ Naresh Chandera Sharma ${ }^{(c)}$}

\footnotetext{
(a) BioSci America, Las Vegas, NV, USA.

(b) Johnson \& Johnson Consumer Companies, Inc., Morris Plains, NJ, USA.
}

(c)BioSci Canada, Mississauga, ON, Canada.

\begin{abstract}
The objective of this randomized, examiner blind, parallel group, controlled clinical trial was to compare the antiplaque and antigingivitis efficacy of an essential oil-containing mouthrinse (EO) to two mouthrinses containing $0.05 \%$ Cetylpyridinium Chloride (CPC), one with alcohol and one alcohol-free, using a two-week experimental gingivitis validated-model with a $5 \%$ hydroalcohol rinse serving as the negative control. One hundred and fifty-nine subjects, 56 males and 103 females; ranging in age from 18 to 58 years in good general health were assigned to one of the four treatment groups: EO ( $n=40), 0.05 \%$ CPC with alcohol $\left(\mathrm{CPC}_{\mathrm{a}}, \mathrm{n}=39\right), 0.05 \% \mathrm{CPC}$ alcohol-free $\left(\mathrm{CPC}_{\mathrm{na}}, \mathrm{n}=40\right)$, and $5 \%$ hydroalcohol negative control $(\mathrm{n}=40)$. The Mean Turesky Modification of the Quigley-Hein Plaque Index (PI) and the Mean Modified Gingival Index (MGI) were the primary efficacy endpoints and were evaluated at baseline and at two weeks. Following baseline examinations, subjects received a complete dental prophylaxis and began supervised rinsing with their assigned mouthrinse twice daily for two weeks, as their sole oral hygiene measure; 151 subjects completed the trial. Two weeks after baseline the EO adjusted mean PI and MGI scores were significantly lower than those of both CPC rinses and negative control $(\mathrm{p}<0.001)$. In conclusion, the EO mouthrinse demonstrated significantly greater antiplaque and antigingivitis efficacy than both CPC-containing mouthrinses and the negative control.
\end{abstract}

Descriptors: Dental plaque; Gingivitis / prevention \& control; Antiseptics; Oral hygiene.

\section{Corresponding author:}

Marcelo Werneck Barata Araújo

Johnson \& Johnson Consumer \& Personal

Products Worldwide, A Division of Johnson \&

Johnson Consumer Companies, Inc.

185 Tabor Rd.

Morris Plains - NJ - USA

ZIP 07950

E-mail:maraujo@its.jni.com

Received for publication on Apr 13, 2009

Accepted for publication on Aug 05, 2009 


\section{Introduction}

Dental plaque has been considered the main etiologic agent in the initiation of gingivitis and its progression to periodontitis. ${ }^{1}$ To this day, mechanical methods of dental plaque removal are widely regarded as being a highly effective means of helping to control progression of dental caries and periodontal diseases, ${ }^{2}$ which rank among the most common diseases in humans. However, for a variety of reasons, this mechanical routine does not appear to be enough for the vast majority of patients, as supported by incidence and prevalence data. For example, gingivitis was present in 63 percent of the adult U.S. population sampled in the Third National Health and Nutrition Examination Survey. ${ }^{3}$ In Latin America, some studies have shown gingivitis prevalence as high as $100 \% .^{4}$

Chemotherapeutic agents can be used as adjuncts to mechanical plaque control ${ }^{5}$ because these agents can provide an additional benefit in helping to control plaque and gingivitis. ${ }^{6}$ Numerous studies support the use of antiseptic-containing mouthrinses as a component of a complete oral hygiene regimen.

An essential oil-containing mouthrinse (EO) has demonstrated significant antiplaque and antigingivitis efficacy in short-term ${ }^{7,8,9}$ and long-term clinical studies $^{6,10,11,12,13}$ designed within the guidelines required by the American Dental Association Council on Scientific Affairs for evaluating the clinical efficacy of chemotherapeutic mouthrinses. ${ }^{14}$ One sixmonth trial ${ }^{15}$ reported antiplaque and antigingivitis efficacy of a cetylpyridinium chloride (CPC) mouthrinse. However, till this date, a comparison of the clinical antiplaque and antigingivitis effectiveness of EO and $0.05 \%$ CPC has not been reported in controlled clinical trials.

The present short-term randomized clinical trial was conducted to compare the antiplaque and antigingivitis efficacy of a fixed combination of essential oils (EO) to $0.05 \%$ CPC-containing mouthrinses, one with alcohol $\left(\mathrm{CPC}_{\mathrm{a}}\right)$ and one alcohol-free formulation $\left(\mathrm{CPC}_{\mathrm{na}}\right)$, in a two week, experimental gingivitis model, with a $5 \%$ hydroalcohol mouthrinse serving as a negative control.

\section{Material and Methods}

This was a single-center, randomized, examiner-blind, parallel-group, two week no oral hygiene controlled clinical trial. The study was conducted in BioSci Research Canada Ltd. (Mississauga, ON, Canada), from February to March 2008. It was calculated that 36 subjects in each group should be included in the study, with a total of 144 subjects. This sample size provides a $90 \%$ power to detect a between-treatment difference of 0.23 for PI and 0.11 for MGI, based on standard deviations of 0.19 for PI and 0.13 for MGI, at the 0.025 significance level, two-sided. The standard deviations estimates were based on a previous study conducted at the same center and with the same examiner (data not published). Attrition of $10 \%$ of the subjects was assumed, therefore 160 subjects were planned to be included.

After approval by the Ethics Review Committee, 159 generally healthy adults meeting the eligibility criteria were assigned to treatment. This study included male and female volunteers 18 to 58 years of age with a minimum of 20 natural teeth, a baseline mean gingival index $\geq 1.95$ according to the Modified Gingival Index, ${ }^{16}$ a baseline mean plaque index $\geq 1.95$ according to the Turesky modification of the Quigley-Hein Plaque Index ${ }^{17}$ and good general and oral health. Exclusion criteria were: presence of moderate (ADA type III, pockets 6 to $7 \mathrm{~mm}$ with bone loss and bleeding on probing) or advanced periodontitis (ADA type IV, pockets $7 \mathrm{~mm}$ or greater, bleeding on probing) based on clinical examination (ADA Type III, IV) and presence of fixed or removable orthodontic appliance or removable partial dentures. All subjects provided written informed consent.

Subjects presented to the clinical site for baseline examinations having refrained from oral hygiene for at least 8 hours, but no more than 18 hours prior to the baseline visit. Following the baseline examinations, qualified subjects were randomized to one of the four treatment groups described in Table 1 and received a complete dental prophylaxis to remove plaque, stain(s) and calculus (confirmed by use of disclosing solution). Immediately following the prophylaxis, subjects were randomized and began rinsing with their assigned mouthrinse, twice daily for two weeks, as the sole oral hygiene mea- 
Table 1 - Study treatment and dosage for the four test groups.

\begin{tabular}{|c|c|}
\hline Study Treatment & Dosage \\
\hline $\begin{array}{l}\text { Essential Oil-containing mouthrinse (EO) - (Johnson \& Johnson, } \\
\text { Morris Plains, NJ, USA) }\end{array}$ & $\begin{array}{l}20 \mathrm{ml} \text { for } 30 \text { s twice daily } \\
\text { for } 2 \text { weeks }\end{array}$ \\
\hline 5\% Hydroalcohol mouthrinse (negative control) & $\begin{array}{l}20 \mathrm{ml} \text { for } 30 \text { s twice daily } \\
\text { for } 2 \text { weeks }\end{array}$ \\
\hline $\begin{array}{l}0.05 \% \text { CPC-containing mouthrinse with alcohol }\left(\mathrm{CPC}_{\mathrm{o}}\right) \text { - } \\
\text { (Colgate Palmolive Company, S. Bernardo do Campo, SP, Brazil) }\end{array}$ & $\begin{array}{l}20 \mathrm{ml} \text { for } 60 \text { s twice daily } \\
\text { for } 2 \text { weeks }\end{array}$ \\
\hline $\begin{array}{l}0.05 \% \text { CPC-containing alcohol-free mouthrinse }\left(\mathrm{CPC}_{n \mathrm{n}}\right) \text { - } \\
\text { (Colgate Palmolive Company, S. Bernardo do Campo, SP, Brazil) }\end{array}$ & $\begin{array}{l}20 \mathrm{ml} \text { for } 60 \text { s twice daily } \\
\text { for } 2 \text { weeks }\end{array}$ \\
\hline
\end{tabular}

sure (no brushing or flossing). Twice daily rinsing was supervised Monday through Friday. Unsupervised rinsing took place on the weekends and was documented in a diary completed by the subject. At the end of the trial (week 2) subjects returned the bottles in order to measure their residual weights. Subjects refrained from the use of test rinses for at least 4 hours prior to the examinations at the two week visit.

Mean Plaque Index (PI) and Mean Modified Gingival Index (MGI) at 2 weeks after baseline were the primary efficacy endpoints. Gingivitis was assessed at baseline and at 2 weeks by scoring the Modified Gingival Index on the buccal and lingual marginal gingivae and interdental papillae of all scorable teeth by a blinded and calibrated examiner. Plaque area was scored at baseline and at 2 weeks by the Turesky modification of the Quigley-Hein Plaque Index, on six surfaces (distobuccal, midbuccal and mesiobuccal, distolingual, midlingual and mesiolingual) of all scorable teeth, following disclosing. The examiner was previously calibrated (correlation coefficients were at least 0.9 for PI and for MGI). An oral examination was conducted at baseline and final visit to monitor oral tissues. The examiner evaluated the buccal, labial and sublingual mucosa, tongue, hard and soft palate, uvula and oropharynx, and teeth. All subjects who used at least one dose of the study test mouthrinse and had any follow-up information were included in the safety analysis and were monitored for adverse effects.

For each of the primary efficacy variables, treatment means and between-treatment differences at 2 weeks after baseline were assessed by means of a one-way analysis of covariance (ANCOVA) model with treatment as a factor and the corresponding baseline value as a covariate. In order to compare the EO with CPC-containing rinses, it was required that the EO be significantly better than the negative control with respect to both PI and MGI. Comparisons were each tested at the 0.05 level, two-sided. Comparisons between the EO and the two CPCcontaining mouthrinses with respect to PI and MGI used a Bonferroni-type multiplicity adjustment. In each case the test significance level was 0.025 , with one exception: If the EO rinse was concluded superior to at least one of the CPC-containing rinses with respect to both PI and MGI, in each case using a test significance level of 0.025 , two-sided, the corresponding statistical inference for the $\mathrm{EO}$ rinse vs. the other CPC-containing rinse would be reconsidered based on a test significance level of 0.05 , for both PI and MGI. This procedure controls the family-wise type I error rate at $5 \%$.

\section{Results}

Of the 159 randomized subjects, 151 completed the study $\left(\mathrm{EO}=39 ; \mathrm{CPC}_{\mathrm{a}}=37 ; \mathrm{CPC}_{\mathrm{na}}=37\right.$; negative control $=38$ ). Subjects ranged in age from 18 to 58 years old with a mean of 30.7 years. The majority of the subjects were female $(64.8 \%)$, Caucasian $(50.9 \%)$; non-smokers $(74.2 \%)$, and none of the subjects were smokeless tobacco users. Treatment groups were balanced with respect to all baseline characteristics. The distribution of the subjects according to demographic variables is shown in Table 2.

At two weeks, the $\mathrm{CPC}_{\mathrm{na}}, \mathrm{CPC}_{\mathrm{a}}$ and $\mathrm{EO}$ groups presented statistically significantly lower mean PI scores than the negative control $(\mathrm{p}<0.025)$, with percent reductions of $6.2 \%, 9.4 \%$ and $21.2 \%$, respectively. Furthermore, EO PI scores were statistically significantly lower than both CPC rinses 
Table 2 - Distribution of subjects according to demographic characteristics.

\begin{tabular}{c|c|c|c|c|c|c}
\hline \multicolumn{2}{c|}{} & $\begin{array}{c}\text { Negative Control } \\
(\mathrm{N}=40)\end{array}$ & $\begin{array}{c}\mathrm{CPC}_{\text {na }} \text { Rinse } \\
(\mathrm{N}=40)\end{array}$ & $\begin{array}{c}\text { CPC Rinse } \\
(\mathrm{N}=39)\end{array}$ & $\begin{array}{c}\text { EO Rinse } \\
(\mathrm{N}=40)\end{array}$ & $p$ \\
\hline \multirow{2}{*}{ Age (Mean $\pm \mathrm{SD})$} & $29.6 \pm 11.4$ & $31.2 \pm 11.3$ & $29.3 \pm 10.1$ & $32.5 \pm 11.2$ & 0.54 \\
\hline \multirow{2}{*}{ Gender } & Males & $11(27.5 \%)$ & $13(32.5 \%)$ & $16(41.0 \%)$ & $16(40.0 \%)$ & 0.54 \\
\cline { 2 - 7 } & Females & $29(72.5 \%)$ & $27(67.5 \%)$ & $23(59.0 \%)$ & $24(60.0 \%)$ & \\
\hline \multicolumn{2}{c|}{ Smokers } & $32(80.0 \%)$ & $29(72.5 \%)$ & $26(66.7 \%)$ & $31(77.5 \%)$ & \multirow{2}{*}{0.54} \\
\hline \multicolumn{2}{c|}{ Non-smokers } & $8(20.0 \%)$ & $11(27.5 \%)$ & $13(33.3 \%)$ & $9(22.5 \%)$ & \\
\hline
\end{tabular}

Table 3 - Whole Mouth Mean Plaque Index.

\begin{tabular}{l|c|c|c|c}
\hline & $\begin{array}{c}\text { Negative Control } \\
(\mathrm{N}=38)\end{array}$ & $\begin{array}{c}\mathrm{CPC}_{\text {na }} \text { Rinse } \\
(\mathrm{N}=37)\end{array}$ & $\begin{array}{c}\mathrm{CPC}_{\mathrm{a}} \text { Rinse } \\
(\mathrm{N}=37)\end{array}$ & $\begin{array}{c}\text { EO Rinse } \\
(\mathrm{N}=39)\end{array}$ \\
\hline Baseline Means & $2.52 \pm 0.19$ & $2.53 \pm 0.20$ & $2.54 \pm 0.19$ & $2.55 \pm 0.18$ \\
\hline 2 Weeks Adjusted means & $2.64 \pm 0.33$ & $2.48^{\dagger} \pm 0.34$ & $2.39^{\dagger} \pm 0.28$ & $2.08^{\dagger} \pm 0.22^{*}$ \\
\hline Reduction vs. Control & & $6.2 \%$ & $9.4 \%$ & $21.2 \%$ \\
\hline Reduction vs. $\mathrm{CPC}_{\text {na }}$ & & & & $16.0 \%$ \\
\hline Reduction vs. $\mathrm{CPC}_{\mathrm{a}}$ & & & & $13.1 \%$ \\
\hline
\end{tabular}

tStatistically significantly different from Negative Control $(p<0.025)$. *Statistically significantly different from each of the CPC Rinses $(p<0.001)$.

Table 4 - Whole Mouth Mean Modified Gingival Index.

\begin{tabular}{l|c|c|c|c}
\hline & $\begin{array}{c}\text { Negative Control } \\
(\mathrm{N}=38)\end{array}$ & $\begin{array}{c}\mathrm{CPC}_{\text {na }} \text { Rinse } \\
(\mathrm{N}=37)\end{array}$ & $\begin{array}{c}\mathrm{CPC}_{a} \text { Rinse } \\
(\mathrm{N}=37)\end{array}$ & $\begin{array}{c}\text { EO Rinse } \\
(\mathrm{N}=39)\end{array}$ \\
\hline Baseline Means & $2.24 \pm 0.11$ & $2.22 \pm 0.11$ & $2.25 \pm 0.07$ & $2.25 \pm 0.08$ \\
\hline 2 Weeks Adjusted means & $2.27 \pm 0.12$ & $2.13^{\dagger} \pm 0.15$ & $2.14^{\dagger} \pm 0.14$ & $2.00^{\dagger} \pm 0.11^{*}$ \\
\hline Reduction vs. Control & & $6.1 \%$ & $5.8 \%$ & $12.0 \%$ \\
\hline Reduction vs. CPC & & & & $6.3 \%$ \\
\hline Reduction vs. $\mathrm{CPC}_{\mathrm{a}}$ & & & & $6.6 \%$ \\
\hline
\end{tabular}

tStatistically significantly different from Negative Control $(p<0.001)$. *Statistically significantly different from each of the CPC Rinses $(p<0.001)$.

$(\mathrm{p}<0.001)$ with percent reductions of $16 \%$ and $13.1 \%$ compared to the $\mathrm{CPC}_{\mathrm{na}}$ and $\mathrm{CPC}_{\mathrm{a}}$ groups, respectively (Table 3).

Gingivitis adjusted mean scores (Table 4) for the $\mathrm{CPC}_{\text {na }}, \mathrm{CPC}_{\mathrm{a}}$ and $\mathrm{EO}$ groups were statistically significantly lower than the negative control $(\mathrm{p}<0.001)$ group, with percent reductions of $6.1 \%$, $5.8 \%$ and $12 \%$, respectively. Furthermore, the EO group MGI scores were statistically significantly lower than both CPC rinse groups $(\mathrm{p}<0.001)$ with percent reductions of $6.3 \%$ and $6.6 \%$ relative to the $\mathrm{CPC}_{\text {na }}$ and $\mathrm{CPC}_{\mathrm{a}}$ groups, respectively.

No subject experienced any adverse event during the study. Furthermore, no serious adverse events occurred during the study or the 30 days following the last application of the study treatment.

\section{Discussion}

The results of this trial demonstrated that the use of the EO mouthrinse resulted in significantly greater plaque and gingivitis reductions than both the $0.05 \%$ CPC-containing mouthrinses $\left(\mathrm{CPC}_{\mathrm{na}}\right.$ and $\left.\mathrm{CPC}_{\mathrm{a}}\right)$.

There are very few full reports published on the antiplaque and antigingivitis efficacy of $0.05 \%$ CPC rinses tested in our clinical study. After extended literature search, the only full report found was the article by Allen et al. ${ }^{15}$ (1998), that reported percent reductions $v$ s. control of $24 \%$ for plaque and gingivitis. In addition, an abstract was found; however, there is not enough information regarding the specific product tested and the long term effect of the $0.05 \%$ CPC mouthrinse. ${ }^{18}$

Recently, Gunsolley ${ }^{19}$ (2006) published a meta- 
analysis of six-month clinical trials evaluating the antiplaque and antigingivitis efficacy of mouthrinses, including published studies as well as unpublished data that was provided by the product manufacturers. The results of the meta-analysis included data for over-the-counter mouthrinses containing a fixed combination of essential oils (EO) or cetylpyridinium chloride (CPC), and revealed that EO demonstrated antiplaque and antigingivitis efficacy in clinical trials. However, the author could not draw a conclusion regarding the efficacy of CPC-containing mouthrinses. The formulations of the CPC-containing mouthrinses varied, with concentrations ranging from 0.045 to $0.07 \%$ CPC.

In addition to clinical trials, ex vivo laboratory models have also been used to assess the efficacy of commercially available mouthrinses by providing a mechanistic rationale for a variety of therapeutic effects including antimicrobial efficacy ${ }^{20}$ and effect on oral biofilm formation. ${ }^{21}$ Three ex vivo studies ${ }^{22,23,24}$ showed that an EO rinse was up to two times more effective in killing oral-biofilm bacteria than three different $0.05 \%$ CPC formulations. However, till this date, a comparison of the clinical antiplaque and antigingivitis effectiveness of EO and $0.05 \%$ $\mathrm{CPC}$ has not been reported in controlled trials. As far as we know, this is the first published trial that directly compared the antiplaque and antigingivitis efficacy of EO and CPC rinses, which limits the possibility of comparison with the literature.

In the present study, a short-term experimental gingivitis model was used. In 1965, Löe et al. ${ }^{1}$ showed that people will generally develop gingivitis after 10-21 days of plaque accumulation using a 3 week experimental gingivitis study model. Clinical trials utilizing experimental gingivitis models have been frequently used as a short-term model to evaluate the antiplaque and antigingivitis efficacy of mouthrinses containing antimicrobial agents. These trials have tested a fixed combination of essential oils, ${ }^{8,9} \quad 0.12 \%$ chlorhexidine gluconate, ${ }^{25,26}$ cetylpyridinium chloride, ${ }^{27} 0.1 \%$ hexetidine, ${ }^{28}$ and other noncommercial antimicrobial agents. ${ }^{29}$ Therefore, there is enough evidence to support that experimental gingivitis study designs, like long-term models, have been accepted as a valid model to determine and compare efficacy of antiseptic mouthrinses. ${ }^{30}$ It is also important to point out that this model allows estimation of the effect of the mouthrinse use, without the influence of the mechanical plaque control.

The present study confirms the antiplaque and antigingivitis efficacy of an EO mouthrinse which has been demonstrated in short-term, ${ }^{7,8,9}$ as well as in longer-term studies ${ }^{6,10,11,12,13}$ following the ADA guidelines for clinical trials. These studies showed up to $56 \%$ greater plaque reduction and up to $34 \%$ greater gingivitis reduction than control in subjects with mild-to-moderate plaque and gingivitis. ${ }^{19}$

The results of this study demonstrated all rinses to have statistically significantly better efficacy than the negative control rinse. The EO-containing rinse presented percent reductions $v s$. negative control in PI and MGI of $21.2 \%$ and $12.0 \%$, respectively. $\mathrm{CPC}_{\mathrm{na}}$ provided percent reductions (compared to negative control) of $6.2 \%$ and $6.1 \%$, and $\mathrm{CPC}_{a}$ showed reductions of $9.4 \%$ and $5.8 \%$ for PI and MGI, respectively.

Finally, the present study showed greater antiplaque and antigingivitis efficacy for the EO-containing mouthrinse when compared to the $0.05 \%$ CPC-containing mouthrinses. These differences between the $\mathrm{EO}$ and $\mathrm{CPC}$-containing mouthrinses were statistically significant $(\mathrm{p}<0.001)$. The EO group demonstrated $16.0 \%$ and $13.1 \%$ PI reductions and $6.3 \%$ and $6.6 \%$ MGI reductions compared to the $\mathrm{CPC}_{\mathrm{na}}$ and $\mathrm{CPC}_{\mathrm{a}}$ groups, respectively.

It is clear from this study that mouthrinses containing antimicrobial ingredients, such as $0.05 \%$ CPC or a fixed combination of essential oils (EO), are effective antiplaque and antigingivitis agents when used as the only means of oral hygiene. Furthermore these results show clinical proof of the hypothesis that EO containing mouthrinses have superior efficacy when compared to $0.05 \%$ CPC containing mouthrinses, despite the alcohol content or other ingredients in the formula.

\section{Conclusions}

The present study confirms the utility of using a short-term experimental gingivitis clinical study model to compare plaque and gingivitis efficacy of mouthrinses containing antimicrobial ingredients. 
The results of this study confirm the superior efficacy of a mouthrinse containing a fixed combination of essential oils compared to $0.05 \%$ CPC rinses which have previously been observed in ex vivo laboratory studies.

Finally, this clinical report proves that a com-

\section{References}

1. Löe H, Theilade E, Jensen SB. Experimental gingivitis in man. J Periodontol. 1965;36(3):177-87.

2. Axelsson P, Lindhe J. Effect of controlled oral hygiene procedures on caries and periodontal disease in adults. Results after 6 years. J Clin Periodontol. 1981;8(3):239-48.

3. US Department of Health and Human Services. Oral health in America: a report of the surgeon general - executive summary. Rockville, MD: US Department of Health and Human Services, National Institute of Dental and Craniofacial Research, National Institutes of Health; 2000.

4. Oppermann RV. An overview of the epidemiology of periodontal diseases in Latin America. Braz Oral Res. 2007;21(Spec Iss 1):8-15.

5. Addy M. Evaluation of clinical trials of agents and procedures to prevent caries and periodontal disease: choosing products and recommending procedures. Int Dent J. 1995;45(3):18596.

6. Sharma N, Charles CH, Lynch MC, Qaqish J, McGuire JA, Galustians JG et al. Adjunctive benefit of an essential oilcontaining mouthrinse in reducing plaque and gingivitis in patients who brush and floss regularly: a six-month study. J Am Dent Assoc. 2004;135(4):496-504.

7. Lusk SS, Bowers BS, Tow BS, Watson WJ, Moffitt WC. Effects of an oral rinse on experimental gingivitis, plaque formation, and formed plaque. J Am Soc Prev Dent. 1974;4(4):31-3.

8. Mankodi SM, Ross NM, Mostler K. Clinical efficacy of Listerine in inhibiting and reducing plaque and experimental gingivitis. J Clin Periodontol. 1987;14(5):41-3.

9. Ross NM, Mankodi SM, Mostler KL, Charles CH, Bartels LL. Effect of rinsing time on antiplaque-antigingivitis efficacy of Listerine. J Clin Periodontol. 1993;20(4):279-81.

10. Charles CH, Mostler KM, Bartels LL, Mankodi SM. Comparative antiplaque and antigingivitis effectiveness of a chlorhexidine and an essential oil mouthrinse: 6-month clinical trial. J Clin Periodontol. 2004;31(10):878-84.

11. DePaola LG, Overholser CD, Meiller TF, Minah GE, Niehaus C. Chemotherapeutic inhibition of supragingival dental plaque and gingivitis development. J Clin Periodontol. 1989;16(5):311-5.

12. Lamster IB, Alfano MC, Seiger MC, Gordon JM. The effect of Listerine Antiseptic on reduction of existing plaque and gingivitis. Clin Prev Dent. 1983;5:12-6. mercially available, daily-use fixed combination of essential oil mouthrinse has statistically significantly greater antiplaque and antigingivitis efficacy than $0.05 \%$ CPC-containing mouthrinses, with and without alcohol.

13. Overholser CD, Meiller TF, DePaola LG, Minah GE, Niehaus C. Comparative effects of 2 chemotherapeutic mouthrinses on the development of supragingival dental plaque and gingivitis. J Clin Periodontol. 1990;17(8):575-9.

14. American Dental Association Council on Scientific Affairs. Acceptance Program Guidelines: Chemotherapeutic Products for Control of Gingivitis. Chicago: American Dental Association; 1997.

15. Allen DR, Davies R, Bradshaw B, Ellwood R, Simone AJ, Robinson R et al. Efficacy of a mouthrinse containing $0.05 \%$ cetylpyridinium chloride for the control of plaque and gingivitis: a 6-month clinical study in adults. Compend Contin Educ Dent. 1998;19(2 Suppl): 20-6.

16. Lobene RR, Weatherford T, Ross NM, Lamm RA, Menaker L. A Modified Gingival Index for use in clinical trials. Clin Prev Dent. 1986;8(1):3-6.

17. Turesky S, Gilmore ND, Glickman I. Reduced Plaque Formation by the Chloromethyl Analogue of Victamine C. J Periodontol. 1970;41(1):41-3.

18. Trivedi HM, Barnes VM, Tack V, Blanvalet C, Joziak M, Richter R et al. Plaque Control Effect of a Non-Alcohol Cetylpyridinium Chloride Mouth Rinse. J Dent Res. 2006; abstract 2052.

19. Gunsolley JC. A meta-analysis of six-month studies of antiplaque and antigingivitis agents. J Am Dent Assoc. 2006:137(12):1649-57.

20. Bacca LA, Leusch M, Lanzalaco AC, Macksood D, Bouwsma OJ, Shaffer JB et al. A comparison of intraoral antimicrobial effects of stabilized stannous fluoride dentifrice, baking soda/ peroxide dentifrice, conventional $\mathrm{NaF}$ dentifrice and essential oil mouthrinse. J Clin Dent. 1997;8(2):54-61

21. Auschill TM, Hein N, Hellwig E, Follo M, Sculean A, Arweiler NB. Effect of two antimicrobial agents on early in situ biofilm formation. J Clin Periodontol. 2005;32(2):147-52.

22. Araujo MWB, Pan P, Lux R, Shi W. Plaque Biofilm penetration by essential-oil and CPC containing mouthrinses. J Dent Res. 2008; Abstract 0285.

23. Lux R, Pan P, Castaneda SD, Sim JH, Harper DS, Shi W. Biocidal Activity of antiseptic mouthrinses in saliva-derived biofilm model. J Dent Res. 2008; Abstract 1339.

24. Pan P, Lux R, Shi W, Li L, Castaneda SD, Fullem CM et al. Evaluation of Plaque Biofilm Kill Activity of Representative Global Mouthrinses. J Dent Res. 2008; Abstract 31. 
25. Gründemann LJ, Timmerman MF, van der Velden U, van der Weijden GA. Reduction of stain, plaque and gingivitis by mouth rinsing with chlorhexidine and peroxyborate. Ned Tijdschr Tandheelkd. 2002;109(7):255-9.

26. Zanatta FB, Antoniazzi RP, Rösing CK. The effect of $0.12 \%$ chlorhexidine gluconate rinsing on previously plaque-free and plaque-covered surfaces: a randomized, controlled clinical trial. J Periodontol. 2007;78(11):2127-34.

27. Witt JJ, Walters P, Bsoul S, Gibb R, Dunavent J, Putt M. Comparative clinical trial of two antigingivitis mouthrinses. Am J Dent. 2005 Jul;18 Spec No:15A-17A.
28. Sharma NC Galustians HJ, Qaqish J, Charles CH, Vincent JW, McGuire JA. Antiplaque and antigingivitis effectiveness of a hexetidine mouthwash. J Clin Periodontol. 2003 Jul;30(7):590-4.

29. Preus HR, Aass AM, Hansen BF, Moe B, Gjermo P. A randomized, single-blind, parallel-group clinical study to evaluate the effect of soluble beta-1,3/1,6-glucan on experimental gingivitis in man. J Clin Periodontol. 2008;35(3):236-41.

30. Moran J, Pal D, Newcombe R, Addy M. Comparison of a phenolic and a $0.2 \%$ chlorhexidine mouthwash on the development of plaque and gingivitis. Clin Prev Dent. 1991;13(4):31-5. 